\title{
Dynamic Irreducible Water Saturation and Its Determination Method
}

\author{
Jin-You DAI, Jing WANG, Meng KONG ${ }^{a^{*}}$, Hui-Xian ZHANG, Zi-Long LI \\ Petroleum Engineering Department, China University of Petroleum-Beijing, Beijing, China \\ a1612590549@qq.com \\ "Corresponding author
}

\begin{abstract}
Keywords: Drawdown Pressure, Determination Method, Dynamic Irreducible Water Saturation, Oil and Gas Reservoirs.
\end{abstract}

\begin{abstract}
The irreducible water saturation, the saturation of water when it begins to flow, is not a fixed value in the development process, whose numerical value is related to specific reservoir production conditions. Based on the integration of relative permeability curve and mercury intrusion curve, the author studies the change regularity of the irreducible water saturation under different production conditions (drawdown pressure), and puts forward the concept of dynamic irreducible water saturation and its determination method. Taking west Sulige gas field for application example, the actual drawdown pressure is $13.7 \mathrm{MPa}$ and its dynamic irreducible water saturation is $30 \%$. However, the conventional irreducible water saturation is $38 \%$, which is getting from relative permeability curve. By analyzing the differences between two kinds of irreducible water saturation, the author thinks that the dynamic irreducible water saturation is closer to the actual production condition and it can be used in the correction of relative permeability curve and the study of lower limit of reservoir physical property.
\end{abstract}

\section{Introduction}

The irreducible water saturation is an important parameter in reservoir development, which represents the ratio of volumes of the displacement water in the reservoir and the total rock property. And its numerical value is generally determined by relative permeability experimental methods [1]. In reservoir exploitation, the seepage force is the drawdown pressure [2-4]. When the drawdown pressure changes, the amount and the category of the produced water differ, which can initiate and participate in the flow, are different. At the same time, the value of irreducible water saturation varies. Therefore, for a specific reservoir, the irreducible water saturation value is not definite, and it varies with the change of production conditions (drawdown pressure). In order to distinguish from the conventional irreducible water saturation getting from the relative permeability method, the author defines the dynamic irreducible water saturation. How does the dynamic irreducible water saturation vary with the drawdown pressure? What are the differences between the dynamic irreducible water saturation and the conventional irreducible water saturation? To reveal the characteristic of dynamic irreducible water saturation, based on the integration of relative permeability curve and mercury intrusion curve, this paper studies the change regularity of the irreducible water saturation under different production conditions (drawdown pressure), puts forward the concept of the dynamic irreducible water saturation and its determination method, and deeply discusses the differences between dynamic irreducible water saturation and conventional irreducible water saturation.

\section{The meaning of dynamic irreducible water saturation}

The relative permeability curve and mercury intrusion curve can be obtained from the relative permeability experiment and mercury intrusion experiment respectively. Being the responding curve of gas-water percolation, the two curves can be integrated for the research of fluid percolation in the reservoir exploitation (Fig. 1.). In the Figure 1, the relative permeability ( $\mathrm{Kg}, \mathrm{Kw})$ and the water saturation change when the capillary pressure alters. In the practical production, a certain amount of water is produced (the change in water saturation) when the drawdown pressure 
overcomes a certain capillary pressure. Whether the formation water can be produced is mainly dependent on whether the driving force (the drawdown pressure) can overcome the capillary pressure. Thus, according to the relationship between drawdown pressure and capillary pressure, the formation water in the rock pore can be divided into 3 categories in the view of percolation (Fig. 1.):

(1) Unmovable water: the water that cannot be moved because the drawdown pressure is not sufficient to overcome the capillary pressure corresponding to this kind of water. Having the appearance of film, unmovable water is strong bound water that is strictly attached to the surface of the rock grain. The corresponding water saturation is defined as unmovable water saturation, whose maximum value is $\mathrm{Sw} 2$.

(2) Movable water: the water that starts to flow when there is high drawdown pressure in the production. This kind of water is moderate bound water, being in the layer outside the unmovable water. The water saturation corresponding to it is defined as movable water saturation, whose maximum value is Sw1. Sw1 is equivalent to the water saturation in relative permeability curve where formation water starts to flow, namely irreducible water saturation. Sw1 corresponds to the drawdown pressure P1.

(3) Free water: the water that starts to flow when the drawdown pressure is low. This kind of water is weak bound water, being in the layer outside the movable water. The saturation corresponding to it is defined as free water saturation, whose maximum value is Sw0. Sw0 is equivalent to the original water saturation of the reservoir. Sw0 corresponds to the drawdown pressure $\mathrm{P} 0$.

When the drawdown pressure is low, the free water starts to flow firstly; as the drawdown pressure increases gradually, the movable water starts to be driven out apart from the free water, which means the obvious increase in the volume of flowing water. Free water, movable water and unmovable water are identical in essence and continuous in distribution without clear boundary between them, the main distinction between them being the different extent of adhesion. Thus, in practical development, whether the water can be produced and the amount of water production are mainly dependent upon the magnitude of the drawdown pressure P2. Therefore, the dynamic irreducible water saturation is determined by the drawdown pressure $\mathrm{P} 2$. The bigger $\mathrm{P} 2$, the smaller $\mathrm{Sw} 2$ will be. If $\mathrm{P} 2=\mathrm{P} 1, \mathrm{Sw} 2=\mathrm{Sw} 1$, namely, the dynamic irreducible water saturation is equal to the conventional irreducible water saturation. If $\mathrm{P} 2>\mathrm{P} 1, \mathrm{Sw} 2<\mathrm{Sw} 1$, namely, the dynamic irreducible water saturation is less than the conventional irreducible water saturation. If $\mathrm{P} 2<\mathrm{P} 1$, $\mathrm{Sw} 2>\mathrm{Sw}$ 1, that is to say, the dynamic irreducible water saturation is bigger than the conventional irreducible water saturation.

\section{The Determination of Dynamic Irreducible Water Saturation}

For a certain gas reservoir, $\mathrm{Sw} 0$ is determined by core analysis, and $\mathrm{P} 0$ is obtained through the two curves; Sw1 is from the relative permeability curve, and P1 is obtained through the two curves; $\mathrm{P} 2$ is the practical drawdown pressure from the performance data, and Sw2 is obtained through the two curves. Taking Western Sulige gas field for example [5-6], analysis is as follows: 


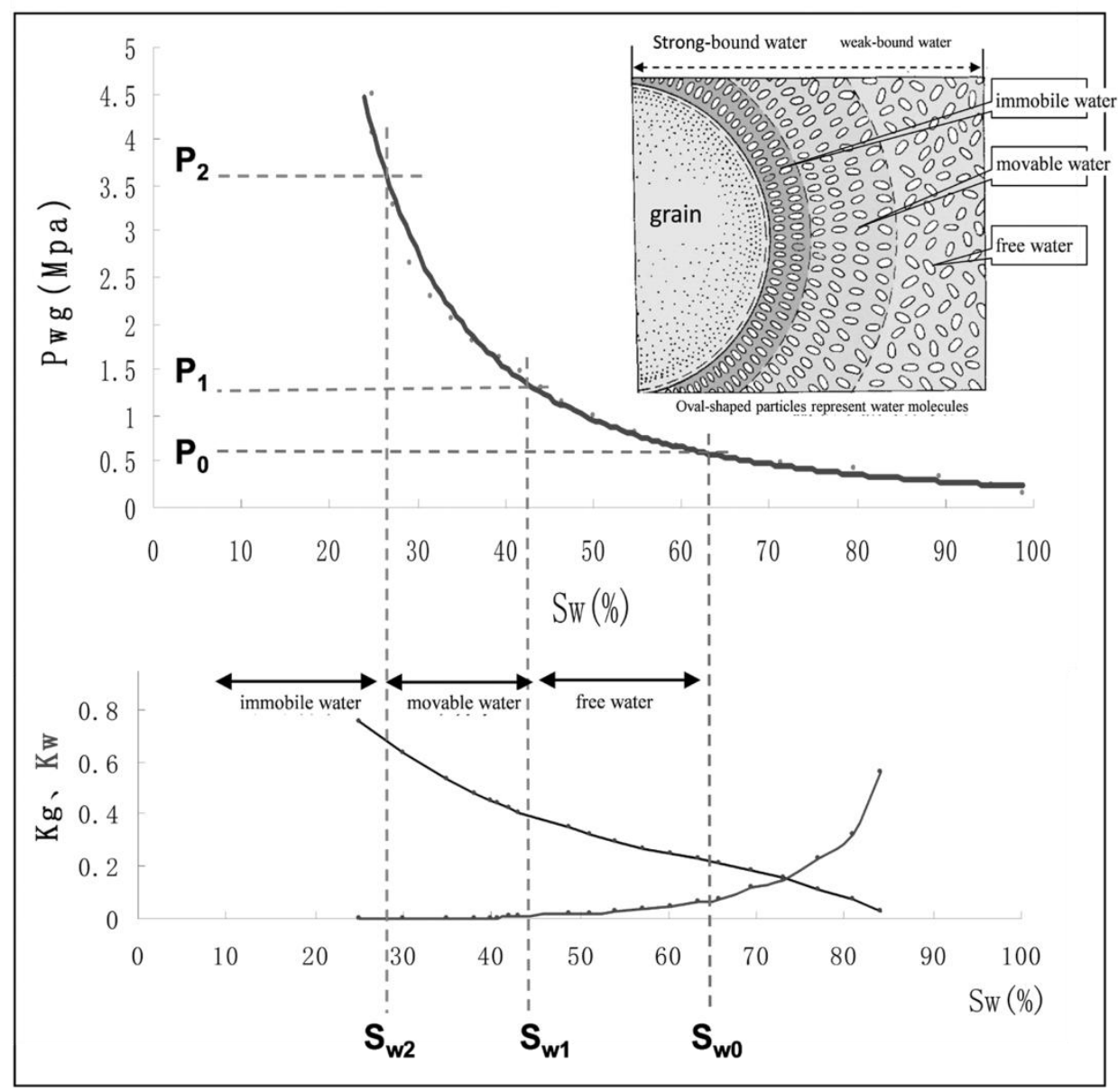

Fig.1 The schematic diagram of immobile water, movable water and free water

Firstly, the Sw0 is determined from the statistical analysis of the water saturation of 8970 pieces of core in 90 wells of Western Sulige gas field (Fig. 2.); then the Sw1 is determined from the average relative permeability curve whose data are from the statistically processed data of 44 gas-drive-water permeability experiments (Fig. 3.); finally, the average mercury intrusion curve is the normalized capillary pressure curve in the gas reservoir condition, which is calculated from the capillary curve in the experiment condition that is based on 385 group of mercury intrusion data (Fig. 4.).

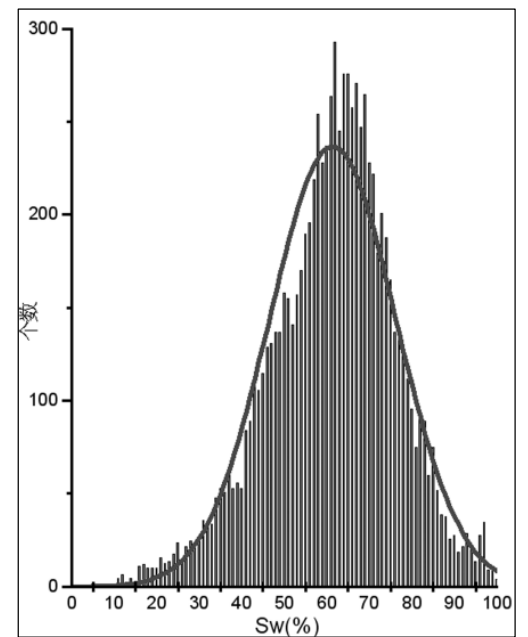

Fig.2 Histogram of core analysis original water saturation

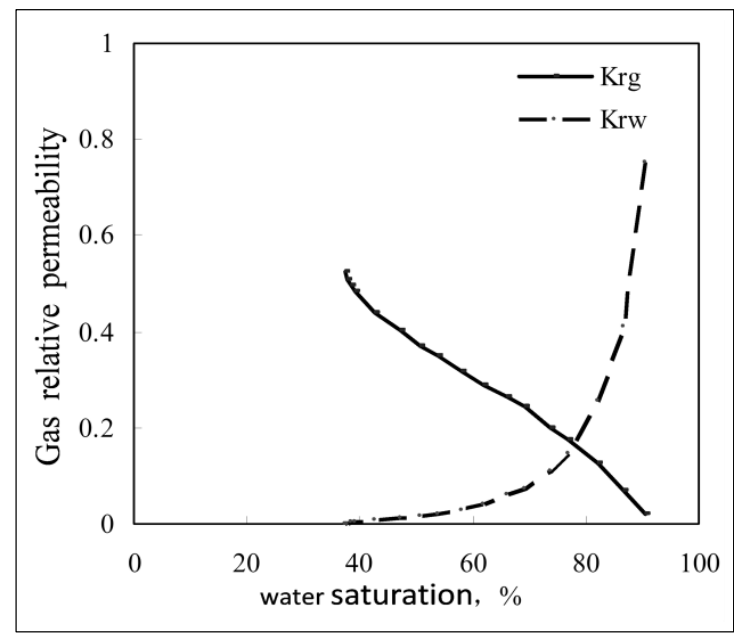

Fig.3 Western Sulige average relative permeability curves

As shown in Fig.2-Fig.4, Sw0 is $61 \%$, and corresponding P0 is $2.6 \mathrm{MPa}$; Sw1 is $38 \%$, and P1 is 
7.6MPa; $\mathrm{P} 2$, the practical drawdown pressure that is calculated statistically, is $13.7 \mathrm{MPa}$, and corresponding Sw2 is 30\%. Therefore, in western Sulige gas field, P2(13.7MPa)>P1(7.6MPa), and $\mathrm{Sw} 2(30 \%)<\mathrm{Sw} 1(38 \%)$. Namely, the dynamic irreducible water saturation is less than the conventional irreducible water saturation, with the gap of $8 \%$.

\section{The Differences between Dynamic Irreducible Water Saturation and Conventional Irreducible Water Saturation}

In the previous research, the irreducible water saturation is viewed as the ratio of the volume of the water that cannot be driven out to the volume of the overall pore in the rock, namely the critical saturation when the water starts to flow in the driving experiment. The irreducible water is considered as a definite value, because the water in the saturation range lower than the irreducible water saturation is in the single phase flowing area, being unable to be driven out (Fig. 1.). However, in the author's opinion, the free water, movable water and unmovable water are identical in essence and continuous in distribution, without clear boundary, their differences being the variation in the extent of adhesion. When the drawdown pressure increases, the irreducible water saturation changes dynamically, as shown in the gradual enlargement of the water range that starts to flow, the convert of more formation water to free water and movable water and the gradual reduction of unmovable water; therefore, the irreducible water saturation obtained from the relative permeability experiment cannot completely represents the saturation value in the practical exploitation condition, and in contrast, the irreducible water saturation corresponding to the drawdown pressure is more likely to reflect the practical condition, being the genuine saturation value in the gas reservoir development. Consequently, the lower limit of reservoir physical property or the dynamic reserves will be closer to the practical production.

In addition, as is shown in relative permeability curve (Fig. 1.), the water saturation is very small and the value of water relative permeability is 0 in movable water range [Sw2, $\mathrm{Sw} 1]$. That is the water cannot flow in this range. If the $\mathrm{Sw} 2$ is the genuine irreducible water saturation, the value of water relative permeability in this saturation range [Sw2, $S w 1]$ should be greater than 0 . This may be related to the experiment condition (the property of the core, fluid and displacing agent which are used for driving, equipment ability, operation procedures and operation people). Because there are variations between relative permeability curve and practical driving curve owing to the deviation between experiment condition and actual formation condition, the correction of the relative permeability curve is needed.

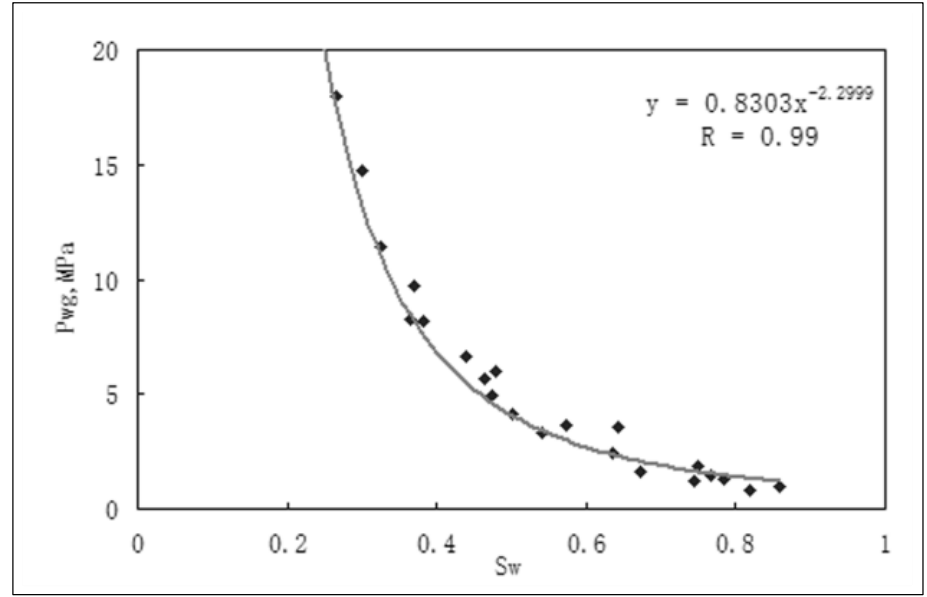

Fig.4 verage mercury curve under the reservoir conditions of Sulige West 


\section{Conclusions and Understanding}

(1) During the gas reservoir exploitation, when the drawdown pressure is different, the water that starts to flow is of distinct kind, and the water producing degree varies. The low drawdown pressure activates free water firstly; as the drawdown pressure increases, movable water starts to flow apart from free water. In the actual exploitation, whether water is produced and the amount of water production is closely related to drawdown pressure. The greater drawdown pressure, the smaller irreducible water saturation and the more produced water will be.

(2) Due to the differences between experimental conditions and objective ground conditions, irreducible water saturation (getting from relative permeability curve) cannot completely represent the real reservoir irreducible water saturation - dynamic irreducible water saturation. The actual producing pressure drop is $13.7 \mathrm{MPa}$ in West Sulige gas field, dynamic irreducible water saturation is $30 \%$, while the irreducible water saturation determined by the relative permeability method is $38 \%$, with the difference of $8 \%$.

(3) Dynamic irreducible water saturation is closer to actual production and has application value, which can be used to correct relative permeability curves, determine reservoir properties lower limits, study dynamic reserves and the degree of producing reserves.

\section{Acknowledgements}

This study is supported by National Science and Technology Major Project 'Geology and technology of enhancing recovery efficiency in complicated oil and gas field' (No. 2008ZX05009-004-03), Foundation of China University of Petroleum-Beijing 'Gas-water distribution regularity and water production mechanism in Liuyangbao gas field' (No. 2462015YQ0214) and National Natural Science Foundation of China 'Controlling mechanism on brittleness of tight sandstone and evaluation of acoustic emission in tight sandstone' (No. 51404282).

\section{References}

[1] Shenglai Yang and Junzhi Wei, Fundamentals of Petrophysics (Petroleum Industry, Beijing, 2004).

[2] Dezhi Zhou, Study of the relation between immobile water saturation and critical water saturation, Petr. Geol. Recov. Eff. 13, 81 (2006).

[3] Zhongxian Qiu, Yuetian Liu, Bin Tu, Theoretical study on low velocity non-Darcy gas flow in low-permeability water-bearing porousmedium, Spec. Oil. Gas. Res. 16, 79 (2009).

[4] Hongqing Song, Weiyao Zhu and Yuguang Zhang et al, Theoretical study on development of low-permeability water-bearing gas reservoir with different horizontal heterogeneous conditions, Spec. Oil. Gas. Res. 15, 45 (2008).

[5] Jinyou Dai, Jianting Li and Baogang Wang et al, Distribution regularity and formation mechanism of gas and water in the western area of Sulige gas field, NW China, Petr. Expl. Develop. 39, 524 (2012).

[6] Jinyou Dai, Leilei Wang and Jianting Li et al, Gas and water distribution and analysis of water production types in western Sulige gas field, Spec. Oil. Gas. Res. 18, 69 (2011).

[7] Jiudi Li, Tao Yan and Tianpei Zhao, Uncertainty Analysis of Calculating Original Oil \& Gas Saturation Using Capillary Pressure Data, Marin. Oil. 25, 11 (2005).

[8] Ci Bao, Natural Gas Geology (Science, Beijing, 1988) pp. 215-217. 